\title{
Zonal expression of dickkopf-3 and components of the Wnt signalling pathways in the human adrenal cortex
}

\author{
T Suwa, M Chen, C L Hawks and P J Hornsby \\ Department of Physiology and Sam and Ann Barshop Center for Longevity and Aging Studies, University of Texas Health Science Center, San Antonio, Texas, \\ USA \\ (Requests for offprints should be addressed to P Hornsby, Sam and Ann Barshop Center for Longevity and Aging Studies, University of Texas Health Science \\ Center, 15355 Lambda Drive STCBM 2·200, San Antonio, TX 78245, USA; Email: hornsby@uthscsa.edu) \\ (T Suwa is now at Third Department of Internal Medicine, Gifu University School of Medicine, Gifu 500-8705, Japan) \\ (M Chen is now at Department of Pathology, Shantou University Medical College, Shantou, Guangdong 515031, People's Republic of China) \\ ( $T$ Suwa and M Chen contributed equally to this work)
}

\begin{abstract}
The mechanisms underlying the differentation of the adrenal cortex into zones are unclear. Microarray studies on RNA from microdissected zona reticularis $(\mathrm{ZR})$ and zona fasciculata/zona glomerulosa $(\mathrm{ZF} / \mathrm{ZG})$ derived from adult human adrenal glands showed that a gene of the dickkopf family $(D K K), D K K 3$, is differentially expressed in the zones. The Dickkopf proteins are morphogens involved in Wnt signalling. Northern blotting showed higher $D K K 3$ transcript levels in $\mathrm{ZF} / \mathrm{ZG}$ than $\mathrm{ZR}$ samples. In situ hybridization on adult human adrenal gland sections showed that $D K K 3$ expression was much higher in the ZG than in the ZF or ZR. DKK3 expression was also higher in the medulla. We screened for expression of other members of the DKK family and the related Wingless-type mouse mammary tumor virus integration site gene family (WNT), frizzled (FZD), and dishevelled (DVL) gene families. Among dickkopf family members, only DKK3 was
\end{abstract}

expressed at a detectable level in both human and mouse adrenocortical RNA samples. Consistent with previously published data on the effects of Wnt4 gene disruption in the mouse, we found only WNT4 expression within the $W N T$ family in both human and mouse RNA. Northern blotting showed that WNT4 was expressed at a higher level in ZF/ZG cells than in ZR. The higher level of DKK3 and WNT4 expression in ZF/ZG cells was confirmed by real-time PCR. In the frizzled and dishevelled families we found FZD1, FZD2 and DVL3 transcripts in human adrenocortical RNA, and FZD2 and DVL3 in mouse adrenocortical RNA. These data show that a variety of genes of the Wnt signalling pathways are expressed in the adrenal cortex. The zonal distribution of $D K K 3$ expression suggests that it could be involved in zonal differentiation or growth.

Journal of Endocrinology (2003) 178, 149-158

\section{Introduction}

The zones of the adrenal cortex have been recognized as morphological entities since the middle of the 19th century. At various times in the past they have been thought of as entirely separate cell types, sustained by proliferation within each zone, but currently it is generally thought that the three zones of the cortex represent forms of differentiation of a single cell type (Wolkersdorfer \& Bornstein 1998, Mitani et al. 1999, Rainey 1999, Whitworth \& Vinson 2000, Alesci \& Bornstein 2001). However, questions of the nature of stem cells within the adrenal cortex, if they exist, have not yet been resolved (Hornsby 2001). The concept that cells of one of the three zonal cell types may re-differentiate into another zonal cell type has been derived from observations on the growth of the adrenal cortex and experiments involving adrenocortical regeneration and cell transplantation (Okamoto et al. 1998, Wolkersdorfer \& Bornstein 1998, Mitani et al. 1999, Teebken \& Scheumann 2000, Hornsby 2001).

The zones have long been known to have distinct physiological roles. The concept that the zona glomerulosa is the part of the cortex responsible for the secretion of aldosterone has long been accepted; more recently, it has become clear that the zona reticularis is responsible for the biosynthesis of dehydroepiandrosterone (DHEA), whereas the zona fasciculata secretes cortisol, but not DHEA (Endoh et al. 1996). There is an increasing understanding of the biochemical and molecular biological differences among the zones (Rainey 1999, Hanley et al. 2001, Raza et al. 2001, Takemori et al. 2001, Bassett et al. 2002), but little is known of the mechanisms by which the zones develop in the fetal and postnatal adrenal gland, or of the 
processes that maintain the zones and regulate their width in the adult. However, recent observations on mice with a disruption of the Wnt4 gene have implicated the Wnt* signalling pathways in adrenocortical zonation (Heikkila et al. 2002). Wnt4 expression is confined to the glomerulosa in newborn wildtype mice; newborn Wnt4-deficient mice had a smaller number of glomerulosa cells and lower plasma aldosterone (Heikkila et al. 2002).

Previously, to address questions of differential gene expression in the zones of the human adrenal cortex, we developed a microdissection technique for the separation of the zona reticularis (ZR) away from the outer zones of the adult human adrenal cortex (Endoh et al. 1996). This dissection produces relatively pure ZR tissue, as shown by the absence of expression of type II $3 \beta$-hydroxysteroid

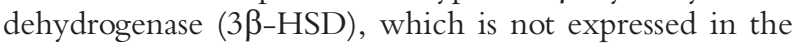
ZR (Endoh et al. 1996). The remaining tissue comprises a mixture of zona fasciculata $(\mathrm{ZF})$ and zona glomerulosa $(\mathrm{ZG})$ cells. Because of the limited extent of the $Z G$ in the adult human adrenal cortex, separation of $Z F$ from $Z G$ was not feasible. These zonal tissue preparations $(\mathrm{ZF} / \mathrm{ZG}$ and ZR) were used to prepare cell cultures, and RNA was prepared from the cultured cells (Endoh et al. 1996). We investigated patterns of gene expression in these separated cell populations (Wang et al. 2001). RNA from ZR and ZF/ZG cells was amplified by PCR; the PCR products were then labelled with ${ }^{32} \mathrm{P}$ and hybridized to arrayed cDNA clones (Wang et al. 2001). We identified 16 genes that showed an average of $>$ twofold differences in hybridizations of four different pairs of ZF/ZG- and ZR-derived samples. Some of these genes were of known function and others had previously been identified as expressed sequence tags (ESTs).

Although these experiments revealed novel differences in gene expression among the zones, the small numbers of genes that can be arrayed on membrane filters limited the conclusions that could be drawn, and the differentially expressed genes that were identified did not appear likely to be involved in zonal differentiation. Therefore, as glass-slide microarrays with much larger numbers of arrayed human genes became available, we applied this technology to increase the number and variety of genes surveyed. We report here that these microarray studies identified a gene of the dickkopf family $(D K K), D K K 3$, as differentially expressed in the zones of the human adrenal cortex. The Dickkopf proteins are secreted factors that act as morphogens by modulating Wnt protein signalling (Glinka et al. 1998, Monaghan et al. 1999, Nusse 2001, Zorn 2001). A major function of the Dickkopf proteins is head induction and limb morphogenesis in the mouse embryo (Mukhopadhyay et al. 2001). Our finding of zonal differences in DKK3 expression prompted us to carry out the studies described here, in which we investigated the expression of DKK3 in more detail and assessed the expression of genes of the Wnt signalling pathway in the human adrenal cortex.

\section{Materials and Methods}

\section{Cell separation and culture}

Adult human adrenal glands were obtained from kidney organ donors under an approved protocol at Baylor College of Medicine. We are grateful to the staff of Lifegift, Houston, for their assistance in providing adrenals from kidney transplants. Donors were of both sexes and were in the range of 20 to 40 years of age.

Zonal tissue preparations were obtained by microdissection (Endoh et al. 1996). The ZR was separated from the rest of the cortex on the basis of colour (the $\mathrm{ZR}$ is brown and the $\mathrm{ZF}$ is bright yellow). The remainder of the cortex was then separated from the capsule, resulting in a tissue preparation comprised largely of ZF with some ZG. Tissue fragments were dissociated to cell suspensions using enzymatic and mechanical dispersal $(3 \mathrm{~h}$ incubation with $1 \mathrm{mg} / \mathrm{ml}$ type I-A collagenase and $0.1 \mathrm{mg} / \mathrm{ml}$ DNAse, both from Sigma Chemical Co., St Louis, MO, USA) (Hornsby \& McAllister 1991).

$\mathrm{ZR}$ and $\mathrm{ZF} / \mathrm{ZG}$ cells were placed in culture for several days before RNA was prepared from them. The culture conditions were as previously described (Hornsby \& McAllister 1991). After 5 days the serum-containing medium was replaced with defined serum-free medium comprising Dulbecco's Eagle's Medium/Ham's F-12 1:1 (Invitrogen) with $200 \mu \mathrm{g} / \mathrm{ml}$ bovine serum albumin (Bayer Pentex cell culture grade), $40 \mu \mathrm{M}$ vitamin $\mathrm{E}$, $2 \mathrm{mM}$ ascorbate, $20 \mathrm{nM}$ selenite (Sigma), without insulin or other hormonal additions. After a 48-h incubation in defined medium, RNA was prepared from the cells using RNAzol B (Tel-Test Inc., Friendswood, TX, USA) following the manufacturer's instructions.

\section{cDNA clones}

cDNAs used as probes for Northern hybridization, for in situ hybridization, and for arraying on nylon membranes were obtained as plasmids produced by the I.M.A.G.E. (Integrated Molecular Analysis of Genomes and their Expression) Consortium project (Lennon et al. 1996) and purchased from Research Genetics (Huntsville, AL, USA). The cDNA clones represented the various members of the DKK, WNT, FZD, and DVL gene families. The cloned fragments were derived from the $3^{\prime}$ untranslated regions of the mRNAs and lacked any sequence similarity to other members of the respective gene families.

\section{Northern blots}

Northern blotting was performed using the NorthernMax kit (Ambion, Austin, TX, USA) following the manufacturer's instructions, with some exceptions. Briefly, RNA samples were separated on formaldehyde gels and blotted 
onto BrightStar-Plus positively charged nylon membranes (Ambion). cDNAs were excised from the I.M.A.G.E. plasmids and were labelled with ${ }^{32} \mathrm{P}$ using random oligonucleotide primers (Feinberg \& Vogelstein 1983). The hybridization conditions were those specified for the NorthernMax kit, but the final wash used was $0 \cdot 2 \times$ SSC (saline sodium citrate), $0 \cdot 5 \%$ sodium dodecyl sulphate, at $65^{\circ} \mathrm{C}$. Blots were exposed to phosphor screens and imaged using a Cyclone storage phosphor system (Packard Bioscience, Meriden, CT, USA).

\section{Microarrays}

RNA obtained from several pairs of ZF/ZG- and ZRderived cell populations were reverse transcribed and amplified as described below. The amplified products were labelled with Cy5 or Cy3 and hybridized to glass slide microarrays bearing 6000 arrayed human cDNAs (Baylor College of Medicine Microarray Core Facility, Houston, TX, USA).

The amplification method used was previously employed to prepare labelled DNA for hybridization to immobilized cDNAs on nylon membranes (Wang et al. 2001); similar procedures have been developed independently and validated for use with microarrays (Puskas et al. 2002). The amplification protocol is an adaptation of the SMART PCR technique developed by Chenchik et al. (1998) $\quad\left(\right.$ SMART $=$ switch mechanism at the $5^{\prime}$ end of RNA templates). The method for reverse transcription and PCR amplification has been described previously (Wang et al. 2001). SMART PCR products were labelled with Cy3-dCTP or Cy5-dCTP using random oligonucleotide primers (Feinberg \& Vogelstein 1983). Conditions for hybridization and washing were standard for microarrays (Puskas et al. 2002). Slides were scanned using a GSI Lumonics ScanArray 5000 (Ottawa, Ontario, Canada). Scanned images were analysed using 'ScanAlyze' and hierarchical clustering analysis (Eisen et al. 1998).

\section{Filter arrays}

Arrays of selected plasmid cDNA clones were prepared using a published procedure (Jin et al. 1997). SMART PCR products were labelled with ${ }^{32} \mathrm{P}$ and hybridized to these filter arrays as described previously (Wang et al. 2001).

\section{Immunocytochemistry}

Portions of human adrenal glands were fixed in $4 \%$ paraformaldehyde and were dehydrated and embedded in paraffin using standard techniques. Sections $(4 \mu \mathrm{m})$ were deparaffinized and rehydrated using graded alcohol concentrations. Antigen retrieval was performed by incubation in $100 \mathrm{mM}$ sodium citrate $\mathrm{pH} 6.0$, and were subjected to three cycles of heating in a microwave oven for $3 \mathrm{~min}$ followed by $10 \mathrm{~min}$ of cooling. After nonspecific binding was blocked with $10 \%$ horse serum (10 min), sections were incubated with goat anti-human Dkk-3 (C-19, sc-14959, Santa Cruz Biotechnology, Santa Cruz, CA, USA) at a 1:10 dilution for $40 \mathrm{~min}$ at room temperature. Bound primary antibody was visualized using the Biotinylated Universal Antibody Vectastain ABC kit (Vector Labs, Burlingame, CA, USA) according to the manufacturer's instructions.

\section{In situ hybridization}

In situ hybridization was carried out on paraffin sections of human adrenal glands using standard procedures (Angerer \& Angerer 1992). ${ }^{35}$ S-Labelled antisense and sense probes against DKK3 and other mRNAs were prepared from I.M.A.G.E. Consortium plasmids using T7 and T3 RNA polymerases. Following hybridization and washing, sections were exposed to single-sided X-ray film (Hyperfilm, Amersham Pharmacia Biotech, Piscataway, NJ, USA). Autoradiographs were scanned at 4800 d.p.i. using a Canoscan D2400UF film scanner (Canon USA, Lake Success, NY, USA).

\section{$R T$-PCR using gene-specific primers}

RNA was reverse transcribed and subjected to PCR amplification as previously described (Suwa et al. 2001). Levels of expression of selected mRNAs were assessed by semi-quantitative competitive RT-PCR using $\beta$-actin as a control mRNA. First-strand cDNA products were used in a PCR reaction with specific primers (FZD1, 5'-CCG ACTGCCAGAGGGAGGATG-3'; 5'-TGACGCTGGC CAAACCCATAC-3'; FZD2, 5'-GCACTACACGCCG CGCATGTC-3'; 5'-CCCACCCCGGGCGGAGGAA AG-3'; DVL3, 5'-CTCCACCAGCTCCTCCATC AC-3'; 5'-CTGGTACGGGAAAGCCATGGG-3'). The reaction was allowed to proceed for 40 cycles, each cycle comprising $20 \mathrm{~s}$ at $95^{\circ} \mathrm{C}, 30 \mathrm{~s}$ at $60^{\circ} \mathrm{C}$, and $1 \mathrm{~min}$ at $72{ }^{\circ} \mathrm{C}$. The products were separated by agarose gel electrophoresis, stained with ethidium bromide and imaged using a gel documentation system (Alpha Innotech, San Leandro, CA, USA).

\section{RT-PCR using gene-family primers}

We used three sets of primers designed to amplify all mRNAs of the WNT, FZD, and DVL families respectively. The sequences of the primers used were those described by Gavin et al. (1990) (WNT family) and Helmbrecht et al. (2001) (FZD and DVL families). SMART PCR products ( $90 \mathrm{ng}$ ) derived as described above were used as templates in PCR reactions. For the WNT family primers we used 40 cycles, each cycle comprising $20 \mathrm{~s}$ at $95^{\circ} \mathrm{C}, 1.5 \mathrm{~min}$ at $50{ }^{\circ} \mathrm{C}, 1 \mathrm{~min}$ at $72{ }^{\circ} \mathrm{C}$; for primers for the FZD and DVL families, we used 


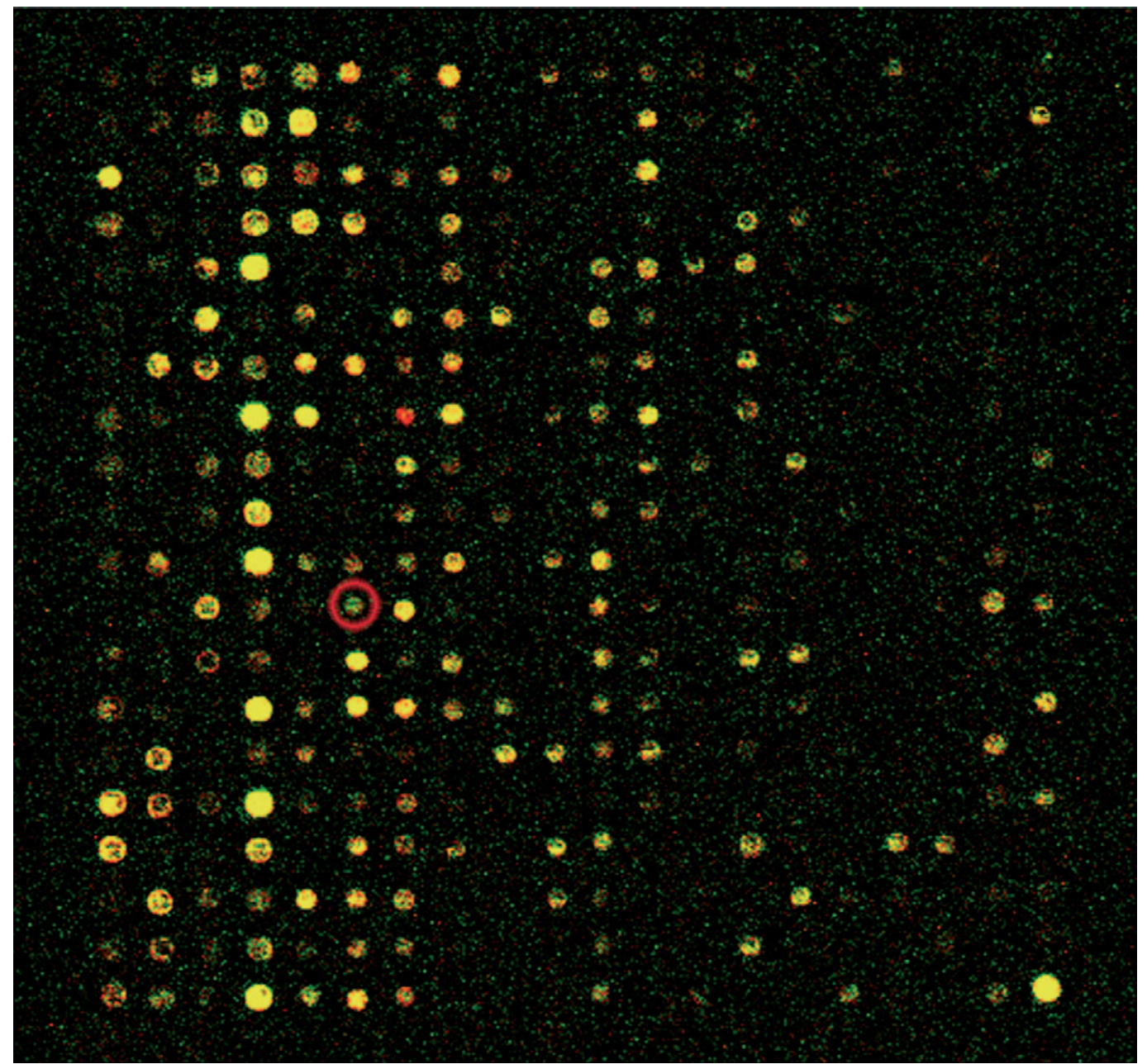

Figure 1 Microarray analysis of differentially expressed genes in the human adrenal cortex. Shown here is the image of a portion of a cDNA microarray following hybridization with Cy5-labelled ZR RNA (red) and Cy3-labelled ZF/ZG RNA (green). The arrayed DKK3 CDNA spot (circled) appears green. Note that the level of hybridization to this spot on the array is low. The differential hybridization was discovered by systematic examination of all spots with greater than twofold differences in normalized green/red fluorescence.

40 cycles, each cycle comprising $20 \mathrm{~s}$ at $95^{\circ} \mathrm{C}, 30 \mathrm{~s}$ at $55{ }^{\circ} \mathrm{C}, 1 \mathrm{~min}$ at $72{ }^{\circ} \mathrm{C}$. The products of the reactions were cloned into the pCRII-TOPO vector (Invitrogen, Carlsbad, CA, USA) for sequencing.

\section{Real-time PCR studies}

Real-time PCR was performed on RNA samples from separated ZF/ZG and ZR cells. Primers were those predicted to be optimal by the program Primer Express (Applied Biosystems, Foster City, CA, USA). Reverse transcription and PCR were performed using the protocols supplied by Applied Biosystems, using a model ABI 7900 HT real-time PCR machine. Accumulation of PCR products was measured by SYBR green fluorescence. For each RNA sample, 3 to 5 cDNA concentrations were assayed, each cDNA concentration being used in triplicate wells. Analysis of data was performed using SDS software from the manufacturer. The number of cycles required to produce the threshold level of PCR product was determined. For each sample pair and for each gene, the difference in threshold cycles was calculated and was normalized with respect to the threshold cycle values for $\beta$-actin.

\section{Results}

We used microarray technology to examine differences in gene expression between $\mathrm{ZR}$ cells and cells from the outer zones $(\mathrm{ZF} / \mathrm{ZG}) . \mathrm{ZR}$ and $\mathrm{ZF} / \mathrm{ZG}$ cells were placed in culture before being used as a source of RNA. The 
intention of this short period in culture was to allow them to recover from the processes of harvesting of the tissues and preparation of the cell suspension, which could affect gene expression. Culturing the cells also ensured that dead and damaged cells were not included in the population used for preparation of RNA, and allowed assessment of the contamination of the cell population by nonadrenocortical cells. Cell morphology and rounding in response to adrenocorticotrophin or cyclic AMP (McAllister \& Hornsby 1987) showed that the cell populations comprised $<5 \%$ of other cell types (principally endothelial cells and fibroblasts). No medullary cells survive the dissociation process used.

For microarray analysis we used slides bearing 6000 arrayed human cDNAs. RNA samples from several pairs of ZR- and ZF/ZG-derived preparations were labelled with $\mathrm{Cy} 5$ or $\mathrm{Cy} 3$ for hybridization to the arrays. This analysis revealed several novel differences in gene expression between the zones ( $\mathrm{T}$ Suwa and PJ Hornsby, unpublished observations). The present work was initiated when we observed that $D K K 3$ was expressed at a higher level in ZF/ZG samples (Fig. 1). This finding suggested that it would be fruitful to investigate the expression of this and other genes involved in Wnt signalling.

In order to validate the differential zonal expression of $D K K 3$, we analysed ZR and ZF/ZG RNA samples by conventional Northern blotting (Fig. 2). Hybridization of blots with a specific $D K K 3$ probe showed a transcript of the expected size $(\sim 2.6 \mathrm{~kb})$ (Krupnik et al. 1999). This transcript was present at much lower levels in the $\mathrm{ZR}$ samples than in the ZF/ZG samples. Rehybridization of blots with probes for steroidogenic enzyme genes showed that the zonal difference in expression of $D K K 3$ was specific. Type II 3ß-hydroxysteroid dehydrogenase (HSD3B2) was much higher in $\mathrm{ZF} / \mathrm{ZG}$ samples than in ZR, as expected (Endoh et al. 1996). Another steroidogenic enzyme gene, cholesterol side-chain cleavage enzyme (CYP11A1) was expressed in both zones, although it was noted to be variably somewhat higher in $\mathrm{ZR}$ samples. Rehybridization of the blots with an oligonucleotide probe for $28 \mathrm{~S}$ ribosomal RNA verified the presence of equal amounts of RNA on the blots.

The microarray analysis and the Northern blot studies were performed using RNA prepared from microdissected adrenal cortex tissue. These results allowed the conclusion that DKK3 mRNA levels are lower in ZR cells, but did not precisely determine the primary location of $D K K 3$ expression in the outer adrenal cortex. Because the $\mathrm{ZG}$ is very thin in most glands, it was not possible to reliably separate this layer from the $\mathrm{ZF}$ by microdissection. In order to address these issues, we performed in situ hybridization on adult human adrenal gland sections (Fig. 3). In situ hybridization performed on several glands showed that $D K K 3$ expression was in fact higher in the $\mathrm{ZG}$ than in the ZF or ZR. Comparisons of the autoradiographic images and conventional histological images showed an
F/G R F/G R

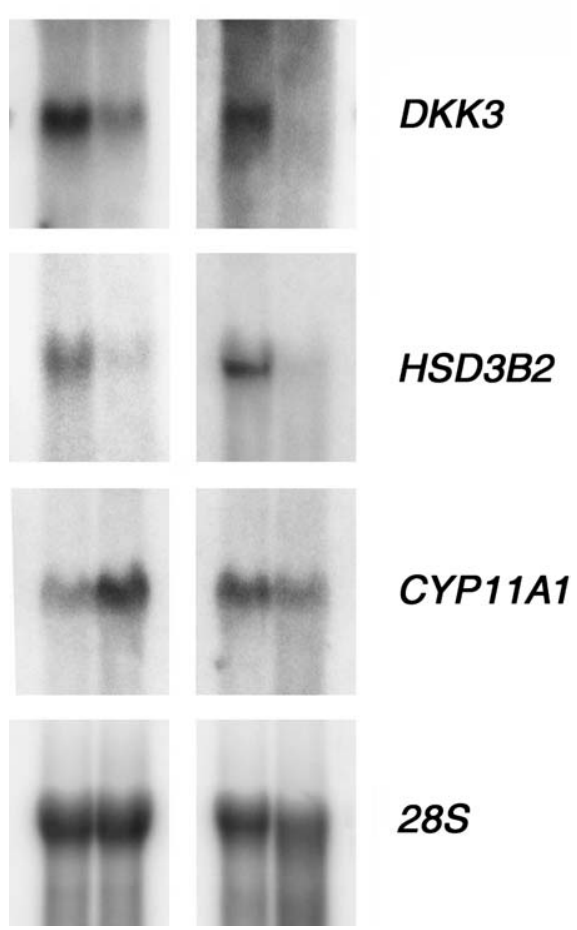

Figure 2 Expression of $D D K 3$ in microdissected zones of the human adrenal cortex. RNA from two different pairs of ZR (R)and $Z F / Z G(F / G)$-derived samples ( $10 \mu \mathrm{g}$ per lane) was hybridized with a $D K K 3$ CDNA probe. The blots were rehybridized with cDNA probes for type II 33-hydroxysteroid dehydrogenase (HSD3B2), cholesterol side-chain cleavage enzyme (CYP11A1), and with an oligonucleotide against $28 \mathrm{~S}$ ribosomal RNA. For the sample pair on the right, the hybridization with HSD3B2 is from a separate blot, as the rehybridization of the DKK3-probed blot failed for technical reasons.

excellent correlation between the zone of DKK3 expression and the morphological ZG. The expression in the ZF and the ZR was not zero, as shown by comparison with the level of radioactivity on sections hybridized with a sense probe. However, there was no detectable difference in DKK3 expression level between the ZF and the ZR. The autoradiographic data also revealed that DKK3 expression was higher in the medulla. Because medullary tissue is not present in most regions of the adult adrenal gland, as shown by the first section used in Fig. 3, we also used sections from portions of a gland adjacent to the central vein, where the medulla is more extensive (Fig. 3). These sections confirmed that the medulla also has a higher expression of $D K K 3$. We then compared the pattern of DKK3 mRNA, as determined by in situ hybridization, with the pattern of Dkk-3 protein, as determined by immunocytochemistry (Fig. 3). Dkk-3 protein was clearly detectable in the medulla, and here the extent of expression determined by immunocytochemistry 

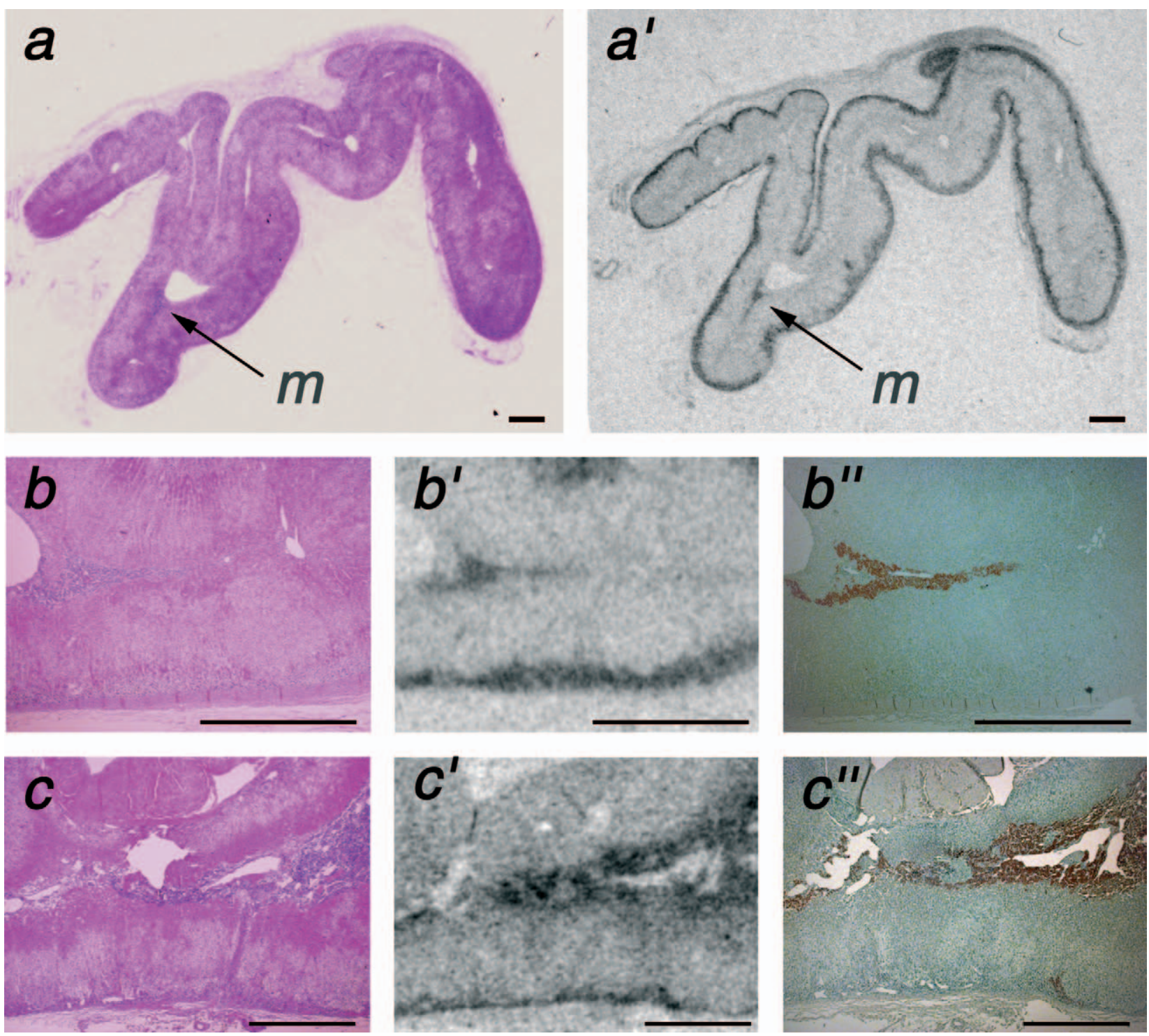

Figure 3 Patterns of expression of DKK3 in the adult human adrenal gland. The sections in series a and $\mathrm{b}$ are from a female aged 40 years, and the sections in series c are from a male aged 36 years. (a, b, c) Sections stained with haematoxylin and eosin; ( $a^{\prime}$, b' and $\left.c^{\prime}\right)$ autoradiographic images resulting from in situ hybridization with an antisense probe for $D K K 3$; ( $b^{\prime \prime}$ and $\mathrm{c}^{\prime \prime}$ ) immunocytochemistry using an antibody against Dkk-3. The sections in each series are adjacent but not sequential, and there are, therefore, slight differences in the morphology. The sections in series a show only a very small amount of medullary tissue (marked $\mathrm{m}$ ); the sections in series $\mathrm{b}$ and $\mathrm{c}$ were chosen to show the medulla. The bar in each photomicrograph is $0 \cdot 1 \mathrm{~mm}$.

was the same as the extent determined by in situ hybridization. However, Dkk-3 protein was not detected in the ZG. Reasons for this apparent discrepancy are addressed in the Discussion. The specificity of the antibody staining in the medulla was confirmed by preincubation of the polyclonal antibody with the peptide against which it was raised. In sections from 6 different human adrenal glands, preincubation with the peptide abolished all staining in the medulla.
The observed differential expression of $D K K 3$ in the zones of the human adrenal cortex indicated that it would be worthwhile to investigate the expression of other members of the Wnt signalling pathway. Using arrayed cDNA clones on nylon membranes, we assayed human adrenocortical RNA samples for levels of expression of members of the DKK, WNT, FZD, and DVD gene families, using methods we described previously (Wang et al. 2001). This screening showed that few of these genes 
F/G R

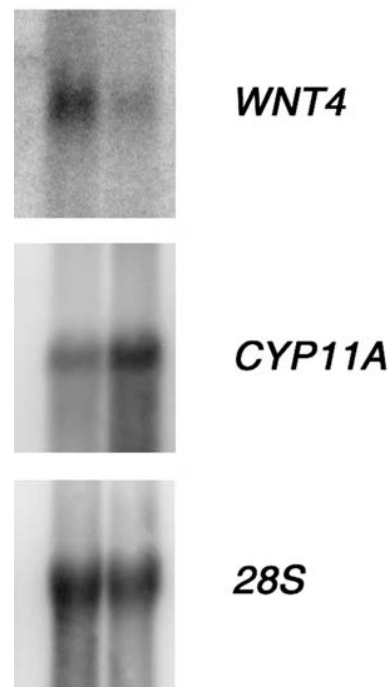

Figure 4 Expression of WNT4 in microdissected zones of the human adrenal cortex. ZR (R)- and ZF/ZG (F/G)-derived RNA (10 $\mu \mathrm{g}$ per lane) was hybridized with a WNT4 cDNA probe. The blot was rehybridized with a CYP11A1 CDNA probe and with an oligonucleotide against $28 \mathrm{~S}$ ribosomal RNA.

were expressed at levels above background. Within the $D K K$ gene family (including the related gene Soggy (Krupnik et al. 1999)) only DKK3 was expressed at detectable levels, whereas DKK1, DKK2 and DKK4 were not above background. In the WNT family, WNT4 was expressed at above background levels; therefore we investigated WNT4 expression by Northern blotting, as described below. However, none of the members of the FZD and DVL gene families were above background, necessitating the use of other detection methods, as also described below. Additionally, we assayed mouse adrenal cortex RNA for expression of these genes, using arrayed mouse cDNA clones of these families. In agreement with the data on human adrenal cortex RNA samples, in the $D K K$ family only $D K K 3$ was expressed at above background levels in mouse adrenal cortex RNA. This was also confirmed by Northern blotting (not shown).

Hybridization of human adrenocortical RNA samples with a WNT4 cDNA probe revealed a band of $\sim 1.1 \mathrm{~kb}$, the expected size of WNT4 mRNA (Fig. 4). The transcript was present at a higher level in ZF/ZG RNA samples than in $\mathrm{ZR}$ samples. Rehybridization with CYP11A1 and 28S probes showed that this result was not caused by uneven loading of RNA on the blot. We followed up on this result by performing in situ hybridization on human adrenal cortex sections using a WNT4 probe, but the level of expression was too low to allow unambiguous determination that the higher level of expression of WNT4 in ZF/ZG samples was the result of higher expression in the $Z G$.
Because $W N T, F Z D$ and $D V L$ are multi-gene families, we performed studies to determine which members of those families are expressed in the adult human adrenal cortex. To do this we performed RT-PCR on human adrenal cortex RNA using primers previously demonstrated to amplify all members of the respective gene family members (see Materials and Methods). When WNT family primers were used, WNT4 was the only transcript amplified ( $3 / 3$ clones sequenced). When FZD primers were used, both FZD1 and FZD2 transcripts were amplified (2/5 and $3 / 5$ respectively), and when DVL primers were used only DVL3 transcripts were amplified (4/4). Similar results were obtained when mouse adrenal cortex RNA was used as template with the same sets of primers. Using $W N T$ primers, $2 / 2$ clones sequenced were WNT4; using FZD primers, only FZD2 was amplified (4/4); with DVL primers, only DVL3 (4/4).

In order to confirm the expression of FZD1, FZD2 and DVL3 in the adrenal cortex, we performed RT-PCR using primers specific for these mRNAs, using both ZF/ZG and ZR RNA samples (Fig. 5). Products of the expected sizes were formed. These experiments demonstrated that all three genes are expressed in the human adrenal cortex. Based on these semi-quantitative RTPCR results, we performed real-time PCR studies on five different pairs of ZF/ZG and ZR RNA samples, using primers for DKK3, WNT4, FZD1, FZD2, and DVL3 (Fig. 5). These data confirm the results obtained by Northern blotting and RT-PCR. DKK3 and WNT4 were consistently expressed at higher levels in $\mathrm{ZF} / \mathrm{ZG}$ samples. There was a trend for FZD2 and DVL3 also to be higher in ZF/ZG samples, but this was not as marked and did not reach statistical significance.

\section{Discussion}

The present studies reinforce the conclusions from recent studies on disruption of the Wnt 4 gene in the mouse (Heikkila et al. 2002) on the significance of Wnt signalling pathways in the adrenal cortex. Patterns of expression of the $D K K 3$ gene suggest that it could be a morphogen in the adrenal cortex. Previous studies of differences in gene expression among the zones have yielded information on receptors, signal transduction mechanisms, and steroid biosynthetic enzymes, but have so far not yielded clues as to the underlying mechanisms of zonal differentiation (Wolkersdorfer \& Bornstein 1998, Mitani et al. 1999, Rainey 1999, Whitworth \& Vinson 2000, Alesci \& Bornstein 2001). In the present experiments we found that the $D K K 3$ gene was expressed in the $\mathrm{ZG}$ at a higher level than in the ZF and ZR. The Dickkopf proteins are secreted modulators of Wnt signalling. Consistent with data from the mouse (Heikkila et al. 2002), the WNT4 gene was also expressed at a higher level in ZF/ZG tissue than in $\mathrm{ZR}$ tissue. The Wnt receptor genes of the frizzled 
F/G R F/G R

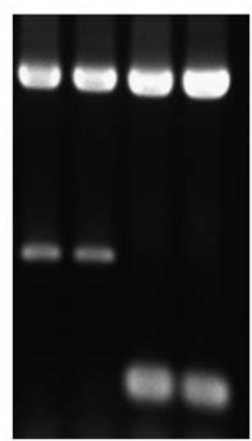

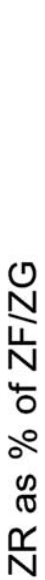

F/G R F/G R

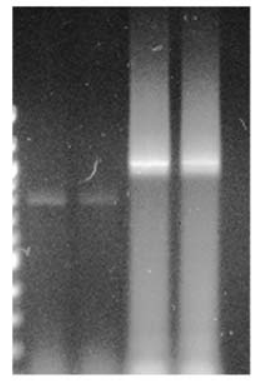

$\beta$-actin

FZD1

DVL3

FZD2

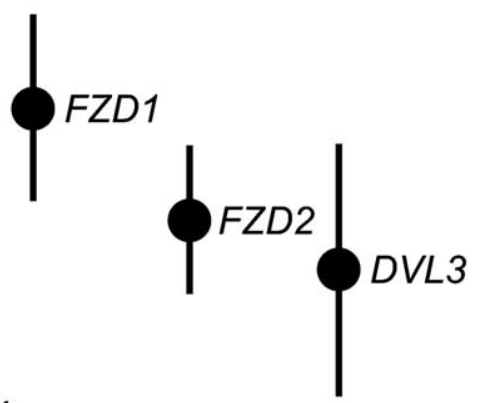

WNT4

Figure 5 (Top) Expression of FZD1, FZD2 and DVL3 in the human adrenal cortex. ZF/ZG $(\mathrm{F} / \mathrm{G})$ and $Z \mathrm{R}(\mathrm{R}) \mathrm{RNA}$ samples were reverse transcribed and used as templates for PCR with gene-specific primers. The PCR products were separated by gel electrophoresis. Primers for $\beta$-actin were used as internal controls in the reactions with FZD2 and DVL3 primers. Because less product was produced in the reaction with FZD1 primers, $\beta$-actin primers were used in separate reactions so that the FZD1-specific product could be clearly observed. (Bottom) Data from real-time PCR measurements, performed as described in Materials and Methods. Five different ZF/ZG and ZR samples were used with primers for the indicated cDNAs. The levels for the ZR samples have been plotted as percentages of the ZF/ZG levels (means \pm standard error). The values for DKK3 and WNT4 are significantly different from $100 \%(P<0 \cdot 05)$ whereas the others are not significantly different.

family (FZD1 and FZD2) were expressed in the human adrenal cortex, as was also DVL3, one of the dishevelled genes which encode proteins that are acted on intracellularly by Frizzled proteins. The observed zonal patterns of expression of Wnt-related genes in the adrenal cortex suggest that the Wnt signalling pathway may be involved in zonal differentiation.

The Wnt family of morphogens was originally characterized as being involved in the early fate of cells within the Drosophila embryo, and subsequently was found to be involved in mammalian embryogenesis (Huelsken \& Birchmeier 2001). More recently these proteins have been shown to be involved in adult stem cell maintenance and tissue regeneration (Austin et al. 1997, Huelsken \& Birchmeier 2001). Moreover, they are now known to play a major role in many cancers, possibly by maintaining cells in a state closer to the stem cell state (Barker \& Clevers 2000, Taipale \& Beachy 2001).

The Dickkopf proteins (Dkk-1, -2, -3 , and -4) have similar structural domains (Krupnik et al. 1999, Brott \& Sokol 2002) but it has not yet been established that they all act via common mechanisms (Krupnik et al. 1999, Mao et al. 2001, Brott \& Sokol 2002, Li et al. 2002, Rothbacher \& Lemaire 2002). A study of the domains of the Dkk 
protein family showed that the C-terminal domains of Dkk-1 and -2 form complexes with LDL receptor-related protein 6 (LRP6), whereas the similar C-terminal domain of Dkk-3 does not (Brott and Sokol 2002). Similarly the C-terminal domains of Dkk-1 and -2 activate the Siamois promoter when co-expressed with LRP6, but the C-terminal domain of Dkk-3 does not (Brott \& Sokol 2002). The possible modes of action of Dkk-3 in mammalian cells therefore remain to be determined. Dkk-3 inhibits cell proliferation in several immortalized cell types, and the DKK3 gene was independently described as reduced expression in immortalized cells (REIC), a possible tumour suppressor gene (Tsuji et al. 2000, 2001). Inhibition of Wnt signalling can also exert a stimulatory effect on cell proliferation (Taipale \& Beachy 2001), but no evidence as to the mechanism of the growth effects of Dkk-3 has yet been presented.

A higher level of DKK3 mRNA was detected in the ZG and in the medulla in these studies, but immunocytochemistry using an antibody against Dkk-3 showed the presence of Dkk-3 protein only in the medulla. An explanation for this result is that it is possible that a tissue such as the adrenal cortex, which is not specialized for protein storage and secretion, may immediately release secretory proteins, whereas part of the normal differentiated function of the medulla is the storage of proteins in secretory granules. However, further studies on the function of Dkk-3 in both the adrenal cortex and the adrenal medulla will be needed to clarify these possibilities.

To our knowledge, this is the first report of compartmentalization of expression of a $D K K$ gene within an endocrine organ. We have preliminary data suggesting that the dickkopf genes may have roles in other endocrine organs. In the mouse ovary, in situ hybridization with a $D K K 3$ probe showed hybridization to follicles but not to the stroma (M Chen and PJ Hornsby, unpublished observations). The latter observation adds to published data showing compartmentalization of WNT and FZD expression in the rat ovary (Ricken et al. 2002). The mechanism by which Dkk-3 may act on adrenocortical cell function, and possibly adrenocortical cell proliferation, certainly cannot be currently determined. Further experiments will be required to elucidate its mechanism of action, and to elucidate the potential role of DKK3 and related genes in adrenocortical zonal differentiation.

\section{Acknowledgement}

This work was supported by a National Institute on Aging grant AG12287.

\section{References}

Alesci S \& Bornstein SR 2001 Intraadrenal mechanisms of DHEA regulation: a hypothesis for adrenopause. Experimental and Clinical Endocrinology and Diabetes 109 75-82.
Angerer LM \& Angerer RC 1992 In situ hybridization to cellular RNA with radiolabeled RNA probes. In In situ Hybridization: A Practical Approach, pp 15-32. Ed. DG Wilkinson. New York: Oxford University Press.

Austin TW, Solar GP, Ziegler FC, Liem L \& Matthews W 1997 A role for the Wnt gene family in hematopoiesis: expansion of multilineage progenitor cells. Blood 89 3624-3635.

Barker N \& Clevers H 2000 Catenins, Wnt signaling and cancer. Bioessays 22 961-965.

Bassett MH, Zhang Y, Clyne C, White PC \& Rainey WE 2002 Differential regulation of aldosterone synthase and $11 \beta$-hydroxylase transcription by steroidogenic factor-1. Journal of Molecular Endocrinology 28 125-135.

Brott BK \& Sokol SY 2002 Regulation of Wnt/LRP signaling by distinct domains of Dickkopf proteins. Molecular Cell Biology 22 6100-6110.

Chenchik A, Zhu YY, Diatchenko L, Li R, Hill J \& Siebert PD 1998 Generation and use of high-quality cDNA from small amounts of total RNA by SMART PCR. In Gene Cloning and Analysis by $R T-P C R$, pp 305-319. Eds P Siebert \& J Larrick. Natick, MA: BioTechniques Books.

Eisen MB, Spellman PT, Brown PO \& Botstein D 1998 Cluster analysis and display of genome-wide expression patterns. PNAS $\mathbf{9 5}$ 14863-14868.

Endoh A, Kristiansen SB, Casson PR, Buster JE \& Hornsby PJ 1996 The zona reticularis is the site of biosynthesis of dehydroepiandrosterone and dehydroepiandrosterone sulfate in the adult human adrenal cortex resulting from its low expression of $3 \beta$-hydroxysteroid dehydrogenase. Journal of Clinical Endocrinology and Metabolism 81 3558-3565.

Feinberg AP \& Vogelstein B 1983 A technique for radiolabeling DNA restriction endonuclease fragments to high specific activity. Analytical Biochemistry 132 6-13.

Gavin BJ, McMahon JA \& McMahon AP 1990 Expression of multiple novel Wnt-1/int-1-related genes during fetal and adult mouse development. Genes and Development 4 2319-2332.

Glinka A, Wu W, Delius H, Monaghan AP, Blumenstock C \& Niehrs C 1998 Dickkopf-1 is a member of a new family of secreted proteins and functions in head induction. Nature 391 357-362.

Hanley NA, Rainey WE, Wilson DI, Ball SG \& Parker KL 2001 Expression profiles of SF-1, DAX1, and CYP17 in the human fetal adrenal gland: potential interactions in gene regulation. Molecular Endocrinology 15 57-68.

Heikkila M, Peltoketo H, Leppaluoto J, Ilves M, Vuolteenaho O \& Vainio S 2002 Wnt-4 deficiency alters mouse adrenal cortex function, reducing aldosterone production. Endocrinology 143 $4358-4365$.

Helmbrecht K, Kispert A, von Wasielewski R \& Brabant G 2001 Identification of a Wnt $/ \beta$-catenin signaling pathway in human thyroid cells. Endocrinology 142 5261-5266.

Hornsby PJ 2001 Transplantation of adrenocortical cells. Reviews in Endocrine and Metabolic Disorders 2 313-321.

Hornsby PJ \& McAllister JM 1991 Culturing steroidogenic cells. In Methods in Enzymology, vol. 206, pp 371-380. Eds MR Waterman \& EF Johnson. San Diego: Academic Press.

Huelsken J \& Birchmeier W 2001 New aspects of Wnt signaling pathways in higher vertebrates. Current Opinions in Genetics and Development 11 547-553.

Jin H, Cheng X, Diatchenko L, Siebert PD \& Huang CC 1997 Differential screening of a subtracted cDNA library: a method to search for genes preferentially expressed in multiple tissues. Biotechniques 23 1084-1086.

Krupnik VE, Sharp JD, Jiang C, Robison K, Chickering TW, Amaravadi L, Brown DE, Guyot D, Mays G, Leiby K, Chang B, Duong T, Goodearl AD, Gearing DP, Sokol SY \& McCarthy SA 1999 Functional and structural diversity of the human Dickkopf gene family. Gene 238 301-313. 
Lennon G, Auffray C, Polymeropoulos M \& Soares MB 1996 The I.M.A.G.E. Consortium: an integrated molecular analysis of genomes and their expression. Genomics 33 151-152.

Li L, Mao J, Sun L, Liu W \& Wu D 2002 Second cysteine-rich domain of Dickkopf-2 activates canonical Wnt signaling pathway via LRP-6 independently of dishevelled. Journal of Biological Chemistry 277 5977-5981.

McAllister JM \& Hornsby PJ 1987 Improved clonal and non-clonal growth of human, rat, and bovine adrenocortical cells in culture. In Vitro Cellular Developmental Biology 23 677-685.

Mao B, Wu W, Li Y, Hoppe D, Stannek P, Glinka A \& Niehrs C 2001 LDL-receptor-related protein 6 is a receptor for Dickkopf proteins. Nature 411 321-325.

Mitani F, Mukai K, Miyamoto H, Suematsu M \& Ishimura Y 1999 Development of functional zonation in the rat adrenal cortex. Endocrinology $1403342-3353$.

Monaghan AP, Kioschis P, Wu W, Zuniga A, Bock D, Poustka A, Delius H \& Niehrs C 1999 Dickkopf genes are co-ordinately expressed in mesodermal lineages. Mechanisms of Development $\mathbf{8 7}$ 45-56.

Mukhopadhyay M, Shtrom S, Rodriguez-Esteban C, Chen L, Tsukui T, Gomer L, Dorward DW, Glinka A, Grinberg A, Huang SP, Niehrs C, Belmonte JC \& Westphal H 2001 Dickkopf1 is required for embryonic head induction and limb morphogenesis in the mouse. Developmental Cell 1 423-434.

Nusse R 2001 Making head or tail of Dickkopf. Nature 411 255-256.

Okamoto M, Takemori H, Halder SK, Nonaka Y \& Hatano O 1998 Implication of ZOG protein (zona glomerulosa-specific protein) in zone development of the adrenal cortex. Endocrine Research $\mathbf{2 4}$ 515-520.

Puskas LG, Zvara A, Hackler L Jr \& Van Hummelen P 2002 RNA amplification results in reproducible microarray data with slight ratio bias. Biotechniques 32 1330-1340.

Rainey WE 1999 Adrenal zonation: clues from 11 $\beta$-hydroxylase and aldosterone synthase. Molecular and Cellular Endocrinology 151 151-160.

Raza FS, Takemori H, Tojo H, Okamoto M \& Vinson GP 2001 Identification of the rat adrenal zona fasciculata/reticularis specific protein, inner zone antigen (IZAg), as the putative membrane progesterone receptor. European Journal of Biochemistry 268 2141-2147.

Ricken A, Lochhead P, Kontogiannea M \& Farookhi R 2002 Wnt signaling in the ovary: identification and compartmentalized expression of wnt-2, wnt-2b, and frizzled-4 mRNAs. Endocrinology 143 2741-2749.

Rothbacher U \& Lemaire P 2002 Creme de la Kremen of Wnt signalling inhibition. Nature Cell Biology 4 E172-E173.

Suwa T, Yang L \& Hornsby PJ 2001 Telomerase activity in primary cultures of normal adrenocortical cells. Journal of Endocrinology $\mathbf{1 7 0}$ 677-684.

Taipale J \& Beachy PA 2001 The Hedgehog and Wnt signalling pathways in cancer. Nature 411 349-354.

Takemori H, Doi J, Katoh Y, Halder SK, Lin XZ, Horike N, Hatano O \& Okamoto M 2001 Characterization of a proximal element in the rat preadipocyte factor-1 (Pref-1) gene promoter. European Journal of Biochemistry 268 205-217.

Teebken OE \& Scheumann GF 2000 Differentiated corticosteroid production and regeneration after selective transplantation of cultured and noncultured adrenocortical cells in the adrenalectomized rat. Transplantation 70 836-843.

Tsuji T, Miyazaki M, Sakaguchi M, Inoue Y \& Namba M 2000 A REIC gene shows down-regulation in human immortalized cells and human tumor-derived cell lines. Biochemical and Biophysical Research Communications 268 20-24.

Tsuji T, Nozaki I, Miyazaki M, Sakaguchi M, Pu H, Hamazaki Y, Iijima O \& Namba M 2001 Antiproliferative activity of REIC/Dkk-3 and its significant down-regulation in non-small-cell lung carcinomas. Biochemical and Biophysical Research Communications 289 257-263.

Wang W, Yang L, Suwa T, Casson PR \& Hornsby PJ 2001 Differentially expressed genes in zona reticularis cells of the human adrenal cortex. Molecular and Cellular Endocrinology 173 127-134.

Whitworth E \& Vinson GP 2000 Zonal differentiation in the rat adrenal cortex. Endocrine Research 26 973-978.

Wolkersdorfer GW \& Bornstein SR 1998 Tissue remodelling in the adrenal gland. Biochemical Pharmacology 56 163-171.

Zorn AM 2001 Wnt signalling: antagonistic Dickkopfs. Current Biology 11 R592-R595.

Received 5 March 2003

Accepted 21 March 2003

Made available as an Accepted Preprint

1 April 2003 